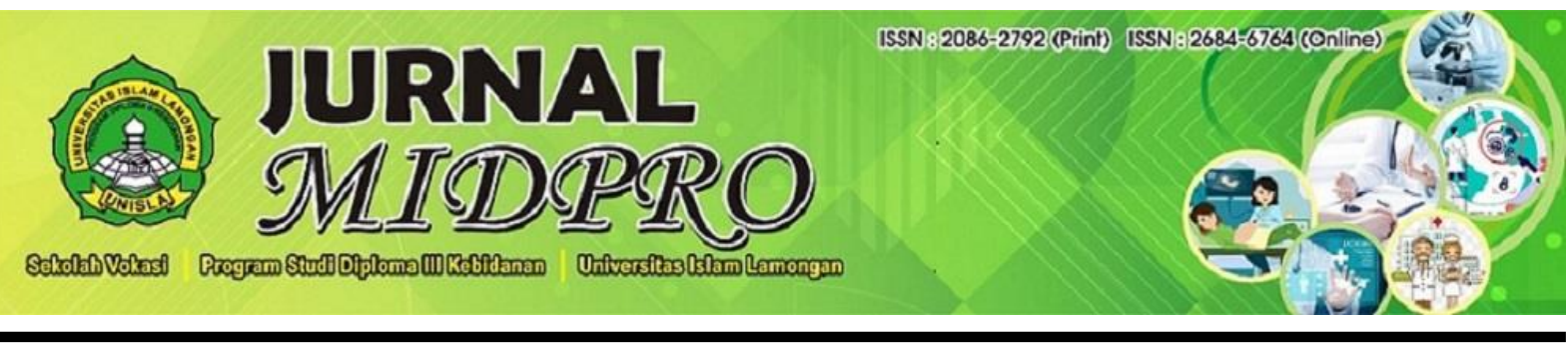

\title{
Validation Of The Cadmium Analysis Method (Cd) by Atomic Absorption Spectrophotometry in Traditional Scrub
}

\author{
Eddy Suhardiana ${ }^{1}$, ${ }^{\mathrm{K}}$ Srie Rezeki Nur Endah ${ }^{2}$ \\ ${ }^{1,2}$ Department of Pharmacy, Faculty of Health Sciences, Perjuangan University Tasikmalaya \\ Correspondence Author Email ( $\left.{ }^{\mathrm{K}}\right)$ : srierezekine@gmail.com
}

\begin{abstract}
Scrub is a type of cosmetics that has been widely used for skin care. However, many women do not realize that among the cosmetic products, including the scrubs they usually use, they may contain dangerous ingredients such as heavy metals. The use of scrubs, especially traditional scrubs that contain ingredients from nature, allows heavy metal contamination. This study aims to validate the analysis method of cadmium heavy metal content in traditional scrubs in the city of Tasikmalaya. Sample preparation used the wet digestion method using HNO3: $\mathrm{H} 2 \mathrm{O} 2$ (3: 1). Cadmium was analyzed by Atomic Absorption Spectrophotometry at a specific wavelength of 283.3 $\mathrm{nm}$, respectively. After obtaining the optimum digestion process and tools, the cadmium method was validated with Atomic Absorption Spectrophotometry (AAS) which included linearity tests, detection limits, quantification limits, precision and accuracy. The results of the validation of the analysis method obtained a linear calibration curve in the concentration range of $1-8 \mathrm{ppm}$ with a linear regression equation $\mathrm{y}=0.1237 \mathrm{x}+0.0247$, the value of the correlation coefficient $=0.9982$. The detection and quantitation limits were $0.63 \mathrm{ppm}$ and $2.11 \mathrm{ppm}$. Intra-day and inter-day precision is SBR <2\%. The retrieval or accuracy obtained is $101.64-105.49 \%$.
\end{abstract}

Keywords : Validation, cadmium, AAS, scrub

\section{Article history :}

Received: 10 Agustus 2020

Received in revised form: 10 September 2020

Accepted: 1 November 2020

Available online: 1 December 2020

licensed by Creative Commons Attribution-ShareAlike 4.0 International License. 


\section{INTRODUCTION}

Body skin care requires special care, can be done traditional or modern. Modern body skin care can be done using a cosmetic scrub made from chemicals and the help of other sophisticated tools. Meanwhile, traditional body skin care can use cosmetic scrubs made from natural ingredients, done manually / traditional tools, and do body massage using olive oil ${ }^{1}$.

Scrub is a type of cosmetics that has been widely used for skin care. However, many women do not realize that among the cosmetic products, including the scrubs they usually use, they may contain dangerous ingredients such as heavy metals ${ }^{2}$. The use of scrubs, especially traditional scrubs that contain ingredients from nature, allows heavy metal contamination ${ }^{3}$.

Heavy metals contained in cosmetics are generally impurities (impurities) in the basic ingredients of making cosmetics. There is a risk of ingesting these heavy metals (contamination from hands) or by inhalation, which may cause other health problems. Heavy metals to watch out for are often contained in cadmium. Cadmium is a soft bluish metal, belonging to the Group II B table periodically with the electronic configuration $[\mathrm{Kr}] 4 \mathrm{~d} 105 \mathrm{~s} 2$. This element has atomic number 48 , has an atomic weight of $112.41 \mathrm{~g} / \mathrm{mol}$ and a density of $8.65 \mathrm{~g} / \mathrm{cm} 3$. Its boiling and melting points are 7650C and $320.90 \mathrm{C}$, respectively ${ }^{4}$. Kadmiun is poisonous to the human body ${ }^{5}$. The half-life is 30 years and accumulates in the kidneys, so that the kidneys experience dysfunction of cadmium, which is found in the human body, mostly obtained through food and tobacco. only a small amount comes from drinking water and air pollution. Determination of heavy metals in cosmetics can be done by wet or dry digestion as measured by Atomic Absorption Spectrophotometer ${ }^{6}$. In previous research, in India, cadmium was determined in cosmetic products using samples of soap, face cream, shampoo, shaving cream and loose powders. Sample preparation was carried out by wet digestion and measured by an Atomic Absorption Spectrophotometer. shaving cream and loose powder. Sample preparation was carried out by wet digestion and measured by an Atomic Absorption Spectrophotometer ${ }^{7}$. shaving cream and loose powder. Sample preparation was carried out by wet digestion and measured by an Atomic Absorption Spectrophotometer ${ }^{8}$.

This study aims to validate the cadmium analysis method contained in traditional scrubs using an experimental research method, namely using the Atomic Absorption Spectrophotometer instrument.

\section{METHOD}

The development of an analytical method for determining cadmium in traditional scrubs begins with an optimization of the Atomic Absorption Spectrophotometer (AAS). After obtaining the optimum conditions for the equipment, the wet digestion process is optimized for the digestion device, which includes the use of various reagents as digesters ${ }^{9}$.

After obtaining the optimum digestion process and tools, the AAS determination method was validated, including linearity test, detection limit, quantification limit, precision and accuracy. The 
stages in the linearity test include making an intermediate standard solution and a working standard solution for making a calibration curve. Detection limits and tool quantization limits are determined statistically from the linear regression equation obtained from the calibration curve. Precision and accuracy are carried out by adding the standard $\mathrm{Cd}$ to the sample. At this stage, it begins with the preparation of the traditional scrub sample by wet digestion to determine the $\mathrm{Cd}$ level ${ }^{10}$.

\section{Linearity}

The linearity test of the analytical method was carried out using a series of standard Cd metal solutions with different concentrations. The calibration curve is obtained by plotting the relationship between the concentration and the measured absorbance or absorbance. As a parameter for the existence of a linear relationship, the correlation coefficient ( $r$ ) and the coefficient of variance of the regression function were used in the linear regression analysis $y=b x+a$. Based on the calibration curve obtained, calculations and statistical tests were carried out including the homogeneity of variance, linearity, detection limit, and quantization limit. The determination of the linearity was carried out by plotting the response of the instrument which was expressed as absorption, with the concentration of the $\mathrm{Cd}$ metal standard solution which consisted of 5 levels of concentration. One standard concentration level is injected 3 times each 11 .

\section{Limit of Detection and Limit of Quantization}

Determination of the limit of detection and limit of quantization was carried out using data from the linearity determination. Determination of the limit of detection and limit of quantization is based on statistically calculated calibration curve ${ }^{10}$.

\section{Accuracy}

The accuracy parameter is determined by calculating the percent of recovery through the standard addition method for cosmetic soap samples. In the cosmetic soap sample, raw metal Cd was added with a known concentration and the percent recovery was calculated ${ }^{10}$.

\section{Precision}

Precision is measured by repeating the measurement of the concentration of the standard compound $\mathrm{Cd}$ in the product 6 times. Weighed carefully an amount of approximately 1 gram of soap, then put into a digestion flask for wet digestion using a mixture of $65 \%$ nitric acid and $30 \%$ hydrogen peroxide. Digestion is done with $65 \%$ nitric acid as much as $15 \mathrm{ml}$ is added to the digestion flask and while heating at a temperature of approximately $100^{\circ} \mathrm{C}$. This process is carried out until the smoke disappears brown. After that, the solution is added with $5 \mathrm{ml}$ of $30 \%$ hydrogen peroxide little by little while heating at a temperature of approximately $100^{\circ} \mathrm{C}$. The digestion process is stopped until the solution is clear which indicates that the digestion process is complete. After the digestion process is complete, the solution is left to cool, then the solution is put into a $50 \mathrm{ml}$ volumetric flask and add distilled water to the boundary mark of the volumetric flask, then the solution is homogenized. Then filtered using filter paper and put into a vial. Sample digestion was carried out twice. The results of measurement of precision are expressed as relative standard deviation (SBR) ${ }^{12}$. 


\section{Specificity}

Specificity parameter testing was not carried out because the hollow cathode lamp used was specific and selective ${ }^{12}$.

\section{RESULTS}

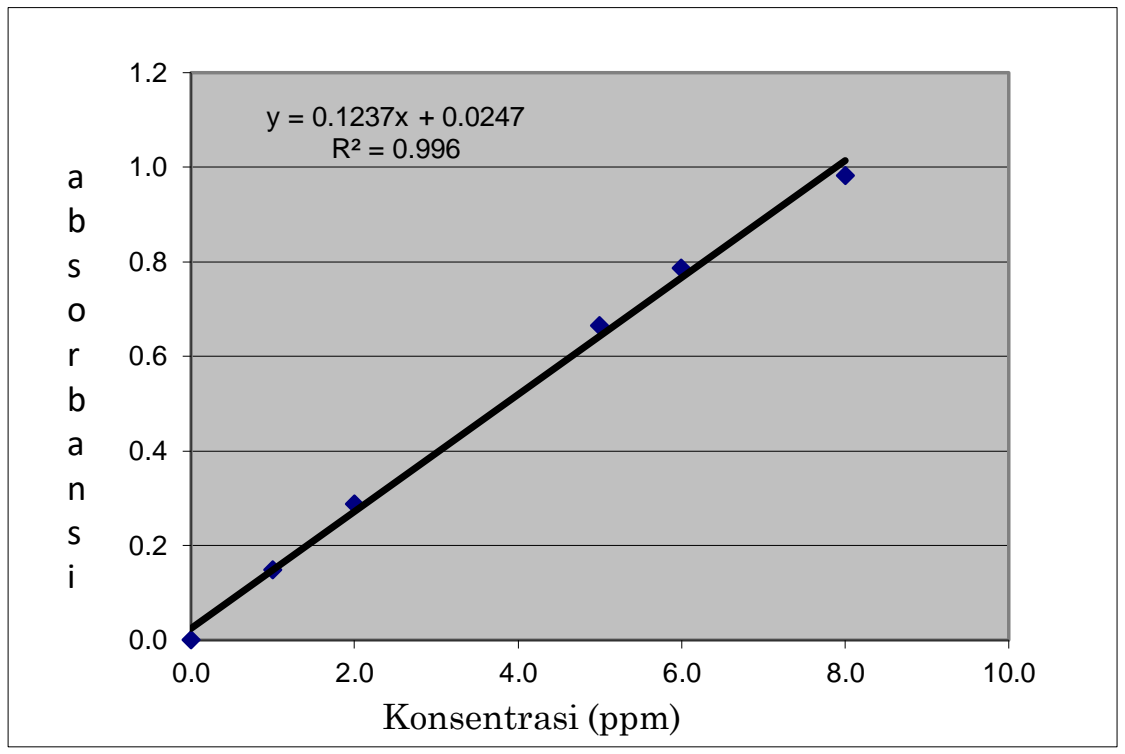

Figure 1. Cd Metal Calibration Curve

Table 1. Parameters of Calibration Curve Linear Regression, LOD / LOQ Cd

\begin{tabular}{ll}
\hline \multicolumn{1}{c}{ Parameter } & \multicolumn{1}{c}{$\mathrm{Cd}$} \\
\hline Regression equation & $\mathrm{y}=0,1237 \mathrm{x}+0,0247$ \\
The slope of the regression line / slope (b) & 0,1237 \\
The y-intercept (a) & 0,0247 \\
X average (ppm) & 3,67 \\
Sy / x (standard deviation of regression) & 0,0260404 \\
(Sy/x)/b & 0,2105122 \\
Vx0 / regression coefficient of variance (\%) & 5,74 \\
r (correlation coefficient) & 0,9982 \\
LOD / Detection Limit (ppm) & 0,63 \\
LOQ / Quantization Limit (ppm) & 2,11 \\
\hline
\end{tabular}


Table 2. Cd Metal Precision in Traditional Scrubs

\begin{tabular}{cccc}
\hline & \multicolumn{3}{c}{ Concentration $(\mu \mathrm{g} / \mathrm{g})$} \\
\cline { 2 - 4 } No & 1 & 2 & 3 \\
\cline { 2 - 4 } & 45,75 & 45,85 & 46,30 \\
2 & 46,20 & 46,35 & 46,55 \\
3 & 44,50 & 45,35 & 44,95 \\
4 & 45,40 & 45,40 & 45,75 \\
5 & 47,00 & 47,00 & 46,20 \\
6 & 47,00 & 46,20 & 46,60 \\
\hline Average & 45,98 & 46,03 & 46,06 \\
SB & 1,59 & 1,09 & 0,97 \\
SBR (\%) & 0,50 & 0,34 & 0,30 \\
KV Horwitz & 19,01 & 19,02 & 19,01 \\
0,67 KV Horwitz & 12,67 & 12,67 & 12,67 \\
HORRAT & 0,04 & 0,02 & 0,02
\end{tabular}

Table 3. Inter-Day Precision of Cd Metal in Traditional Scrubs

\begin{tabular}{lc}
\hline Days to- & Concentration (ppm) \\
\hline 1 & 47,00 \\
2 & 46,60 \\
3 & 46,20 \\
\hline Average & 46,60 \\
SB & 0,69 \\
SBR (\%) & 0,22 \\
KV Horwitz & 19,01 \\
0,67 KV Horwitz & 12,67 \\
HORRAT & 0,02 \\
\hline
\end{tabular}

Tabel 4. Table 4. Accuracy of Cd Metal in Traditional Scrubs

\begin{tabular}{cccccc}
\hline No. & $\begin{array}{c}\text { Concentration of Analyte } \\
\text { without spike }(\mu \mathrm{g} / \mathrm{g})\end{array}$ & $\begin{array}{c}\text { Concentration } \\
\text { of analytes with } \\
\text { spikes }(\mu \mathrm{g} / \mathrm{g})\end{array}$ & $\begin{array}{c}\text { Acquisition } \\
\text { analyte } \\
\text { concentration } \\
(\mu \mathrm{g} / \mathrm{g})\end{array}$ & $\begin{array}{c}\text { Concentration } \\
\text { of added } \\
\text { analytes }(\mu \mathrm{g} /\end{array}$ & Recovery $(\%)$ \\
\hline 1 & 9.42 & 59.94 & 50.52 & 50 & 101.04 \\
2 & 9.42 & 59.94 & 50.52 & 50 & 101.04 \\
3 & 9.42 & 60.35 & 50.92 & 50 & 101.84 \\
5 & 9.42 & 114.11 & 104.68 & 100 & 104.68
\end{tabular}




\begin{tabular}{cccccc}
\hline 6 & 9.42 & 114.11 & 104.68 & 100 & 104.68 \\
7 & 9.42 & 264.40 & 255.05 & 250 & 102.02 \\
8 & 9.42 & 265.68 & 256.26 & 250 & 102.51 \\
9 & 9.42 & 266.09 & 256.66 & 250 & 102.67 \\
\hline \multicolumn{2}{l}{ Average recovery (\%) } & & & 102.89 \\
\hline
\end{tabular}

\section{DISCUSSION}

After the AAS and digestion conditions have been optimum, it can be continued to carry out method verification including linearity, detection limits, quantity limits, accuracy and precision. The determination of the linearity was carried out by plotting the response of the instrument which was expressed by a measured absorbance value, with the concentration of the $\mathrm{Cd}$ metal standard solution consisting of 5 levels of concentration. Each standard concentration is injected 3 times each. Then obtained a calibration curve and determined the correlation parameter (r) and the coefficient of the regression function $(\mathrm{Vx} 0)$.

In Figure 1 it can be seen that the linear regression equation for Cd metal is $y=0.12378 x+0.0247$ $=$ with a correlation coefficient of $r=0.9982$. Furthermore, testing the linearity of the calibration curve is done by calculating all linear regression parameters calculated by statistical equations.

From table 1 it can be seen that the linear regression parameters for $\mathrm{Cd}$ metal in the concentration range of $1.0-8.0 \mathrm{ppm}$ all show good results with the regression line equation $\mathrm{y}=0.1237 \mathrm{x}+0.0247$ and the correlation coefficient $r=0.9982$. The limit of detection (BD) and limit of quantization (BK) were calculated statistically from the calibration curve, namely $0.63 \mathrm{ppm}$ and $2.11 \mathrm{ppm}$.

Precision is a measure of the repeatability of the analytical method and is expressed as the relative standard deviation (SBR) or coefficient of variation (KV). The precision test was carried out with a soap matrix to see the effect of the carrier matrix on the precision results. The precision is carried out by 6 repetitions with the addition of a certain concentration of metal standard to be analyzed and injected 3 times each. The precision test is performed and the relative standard deviation is calculated to meet the acceptance requirements, namely $<2 \%$.

The terms of acceptance are SBR $<0.67 \mathrm{KV}$ Horwitz. The results of Cd metal precision in table 2 obtained that the $\%$ SBR was $0.50 \%, 0.34 \%$ and $0.30 \%$, respectively, which were smaller than $0.67 \mathrm{KV}$ Horwitz. HORRAT $\leq 2$ indicates that the analysis method has sufficient precision. From the results of the precision test, it can be seen that the resulting variation coefficient meets the $\mathrm{KV}$ requirements of the Horwitz trumpet theory and has a HORRAT $\leq 2$, so it is said that the method used meets the precision requirements.

From table 3, it is obtained that the SBR is $0.22 \%$, meets the requirements of $<0.67 \mathrm{KV}$ Horwitz and HORRAT $<2 \%$. Thus the results for the precision parameter met the requirements both inter-day and intra-day. 
The accuracy test for traditional scrubs was carried out using the standard method of addition, by adding a known concentration of ingredients to the soap. The accuracy of $\mathrm{Cd}$ metal is expressed as the percent recovery calculated by the calculation of recovery. From Table 4, the recovery of Cd metal in traditional scrubs is $101.04-105.49 \%$. This fulfills the acceptance requirements for accuracy, which is in the range $80-120 \%$ (Harmita, 2004)

The specificity test was not carried out because the hollow cathode lamp used in atomic absorption spectrophotometry was specific to each type of metal analyzed.

\section{CONCLUSIONS AND SUGGESTIONS}

The method of determining $\mathrm{Cd}$ in traditional scrubs using the Atomic Absorption Spectrophotometer analysis technique has been successfully obtained and meets the validation requirements of the analytical method. The results of the validation of the analysis method show the following results:

a. The linear calibration curve for $\mathrm{Cd}$ metal in the concentration range of 1-8 ppm obtained a linear regression equation $\mathrm{y}=0.1237 \mathrm{x}+0.0247$, the value of the correlation coefficient $=0.9982$

b. The detection and quantitation limits were $0.63 \mathrm{ppm}$ and $2.11 \mathrm{ppm}$ for $\mathrm{Cd}$.

c. Intra-day and inter-day precision, namely SBR $<2 \%$

d. The recoveries for $\mathrm{Cd}$ are $101.64-105.49 \%$. 


\section{REFERENCES}

1. Arbarini A. PENGARUH PENAMBAHAN EKSTRAK RIMPANG KENCUR PADA TEPUNG BERAS TERHADAP SIFAT FISIK KOSMETIK LULUR TRADISIONAL. e-journal. 2015;04:9-15.

2. Volpe MG, Nazzaro M, Coppola R, Rapuano F, Aquino RP. Determination and assessments of selected heavy metals in eye shadow cosmetics from China, Italy, and USA. Microchem J. 2012;101:65-69. doi:10.1016/j.microc.2011.10.008

3. Sayuti, NA., Indarto AS. S. FORMULASI HAND \& BODY LOTION ANTIOKSIDAN EKSTRAK LULUR TRADISIONAL. J Terpadu Ilmu Kesehat. 2016;5(2):174-181.

4. Health C. Guidance on Heavy Metal Impurities in Cosmetics. Published online 2012.

5. BPOM. Per Ka BPOM RI regarding Requirements for Microbial and Heavy Metal Contamination in Cosmetics. Published online 2011.

6. BPOM. Per Ka BPOM RI on Cosmetics Analysis Method. Published online 2011.

7. Chauhan, Amit, Bhadauria R. Determination of Lead and Cadmium in cosmetic product. JChemPharmRes. Published online 2010.

8. Endah S, Surantaatmadja S. The Determination of Heavy Metals Level : Lead in Cosmetic Soap Preparation by Atomic Absorption Spectrophotometer ( AAS ) The Determination of Heavy Metals Level : Lead in Cosmetic Soap Preparation by Atomic Absorption Spectrophotometer. Published online 2019. doi:10.1088/17426596/1179/1/012178

9. Asra, R., \& Yandra RB. Determination of Lead and Cadmium Added in Selected Lipstick Products Sold in Padang City Using Atomic Absorption Spectrophotometry. 2019;02(1):13-18.

10. Endah S. VERIFIKASI METODE PENETAPAN KADAR LOGAM BERAT KADMIUM DALAM SEDIAAN SABUN KOSMETIKA. pharmacoscript. 2018;1(2):121-129.

11. Asra, R. M\& R. ORIGINAL ARTICEL ANALYSIS OF METAL CONTENTS LEAD AND CADMIUM IN URETIC ACID. J Pharm Sci. 2019;2(1):10-16.

12. Sa'adah E, Winata AS. VALIDASI METODE PENGUJIAN LOGAM TEMBAGA PADA PRODUK AIR MINUM DALAM KEMASAN SECARA SPEKTROFOTOMETRI SERAPAN ATOM NYALA. BIOPROPAL Ind. 2010;01(02):31-37. 